\title{
Production of intergeneric allotetraploid between autotetraploid non- heading Chinese cabbage (Brassica campestris ssp. chinensis Makino) and autotetraploid radish (Raphanus sativus L.)
}

\author{
Sun Cheng-Zhen, Li Ying, Zhang Shu-Ning*, Zheng Jin-Shuang \\ State Key Laboratory of Crop Genetics \& Germplasm Enhancement, Horticultural College, Nanjing Agricultural University, Nanjing, 210095, China
}

\begin{abstract}
Intergeneric hybrids between non-heading Chinese cabbage (Brassica campestris ssp. chinensis Makino; $2 \mathrm{n}=4 \mathrm{x}=40$ ) and radish (Raphanus sativus L.; $2 \mathrm{n}=4 \mathrm{x}=36$ ) were obtained through ovary culture and embryo rescue. Some hybrid embryos ( 0.11 per ovary) were produced, but only 4 of them germinated. As most hybrid embryos failed to develop into plantlets directly, plants were regenerated by inducing shoots on the cultured cotyledon and inducing roots on the root induction medium. All hybrid plants were morphologically uniform. They resembled the non-heading Chinese cabbage in the long-lived habit, the plant status, the vernalization requirement and the petiole color, while the petiole shape, leaf venation pattern and flowers were more similar to those of radish. Upon examination of the flowers, these were found to have normal pistil, but rudimentary anthers with non-functional pollen grains. The somatic chromosome number of F1 plants was 38. Analysis of SSR banding patterns provided additional confirmation of hybridity.
\end{abstract}

Keywords: intergeneric allotetraploid; embryo culture; simple sequence repeat

\section{Introduction}

It is estimated that $47 \%$ of all flowering plants and $95 \%$ of all pteridophytes are polyploids and that the majority of these are allopolyploids $[1,2]$, which is a widespread and major force of evolution in plants [3]. Allopolyploidy is often accompanied by major structural, cytogenetic, epigenetic and functional changes to the genome, leading to new phenotypes and to reproductive isolation $[4,5]$. In addition, the permanent heterozygosity fixation of the allopolyploid [6] has the potential to offer a substantial heterozygote advantage. Despite these potential benefits, allopolyploid is an enormous challenge with the orchestration of gene expression, DNA replication, and chromosome pairing. For these reasons, investigation of allopolyploids is very important. The newly synthesized allopolyploid is an ideal model system since it can offer an opportunity to study the response to this genomic change from defined parents.

Allopolyploid formation can occur by two main pathways, the so-called "one-step" and "two-step" models [5]. In the one-step model, the allopolyploid arises directly from an interspecific cross by the fusion of either two unreduced (2n) gametes from diploid parents or two normal $(n=2 x)$ gametes from tetraploid parents. By contrast, in the two-step model,

* Corresponding author. Email: snzhang@njau.edu.cn

Handling Editor: Beata Zagórska-Marek an interspecific F1 hybrid is first formed and the polyploidy is derived from it either from a fertile shoot generated by meristematic tissues having experienced a somatic doubling or by fusion of two $2 \mathrm{n}$ gametes produced by the $\mathrm{F} 1$ hybrid itself [6]. The production of $2 \mathrm{n}$ gametes appears to occur at a surprisingly low rate. Ramsey and Schemske estimated its frequency at $0.56 \%$ [7]. Although with the use of colchicine the frequency of the somatic doubling has increased a lot, the effective diploidization rate is still very low (10.5\%) [8]. In addition, problems with chimeras, abnormal phenotypes and sterility also occur [9]. Little attention, however, has been focused on the use of this method, although a "synthetic" allotetraploid had been obtained by crossing a tetraploid Arabidopsis thaliana $(2 \mathrm{n}=4 \mathrm{x}=20)$ and $A$. arenosa $(2 \mathrm{n}=$ $4 \mathrm{x}=32$ ) [10].

In the crop Brassica, breeders have resorted to varying degrees of hybridization involving close relatives of it in their search for novel traits in developing new and improved varieties [11]. The non-heading Chinese cabbage (Brassica campestris ssp. chinensis Makino) is a main vegetable, which grows in south of China, and it has a long history of cultivation in our country. Radish (Raphanus sativus L.) is cultivated worldwide. It possesses desirable agronomic characters, such as resistance to white rust (Albugo candida) [12], BCN (Heterodera schachtii) [13,14] and culbroot (Plasmodiophora brassicae) [15], as well as resistance to pod shattering [16]. Besides, various related wild species have attracted research attention as potential germplasms 
for improvement of Brassica crops [17]. Therefore, it can be used as a gene donor for the modification of the non-heading Chinese cabbage. Here, we report the successful production of allotetraploid by intergeneric hybridization between autotetraploid non-heading Chinese cabbage (Brassica campestris ssp. chinensis Makino) and autotetraploid radish (Raphanus sativus L.) aimed at enriching the gene pool of the non-heading Chinese cabbage (Brassica campestris ssp. chinensis Makino) and creating useful research material for further understanding of the relationship and the genomic structure between the two genera.

\section{Material and methods}

\section{Plant material and intergeneric hybridization}

The plant material consisted of the two autotetraploid cultivars, non-heading Chinese cabbage (Brassica campestris ssp. chinensis Makino; maternal parent, $2 \mathrm{n}=4 \mathrm{x}=40$ ) and radish (Raphanus sativus L.; paternal parent, $2 \mathrm{n}=4 \mathrm{x}=36$ ). Seeds of two cultivars were grown on experimental fields of Jiangpu Farm, Nanjing Agricultural University. Flowers were protected from foreign pollen two days before anthesis and intergeneric crosses were made by hand.

\section{Embryo culture}

The ovaries were excised 5-10 days after pollination and sterilized with $70 \%$ ethanol for $30 \mathrm{~s}$ followed by a sodium hypochlorite solution containing $1 \%$ active chlorite for 10 min. After washing in sterile distilled water three times, the ovaries were cultured on MS [18] hormone free solid medium containing $500 \mathrm{mg} / \mathrm{l}$ casein hydrolysate. Fifteen days later, the embryos were isolated from the ovaries and transferred to hormone-free MS medium supplemented with $5 \%$ coconut milk and $500 \mathrm{mg} / \mathrm{l}$ casein hydrolysate. As most embryos failed to develop directly into plantlets [19], cotyledons were cut off and cultured on MS medium containing $2 \mathrm{mg} / \mathrm{l}$ 6-benzyladenine (BA) and $0.1 \mathrm{mg} / \mathrm{l} \mathrm{NAA}$ and $5 \%$ coconut milk in order to induce shoot regeneration. After the shoots regenerated, they were transplanted to hormone-free $1 / 2 \mathrm{MS}$ medium supplemented with $0.2 \mathrm{mg} /$ $\mathrm{ml}$ NAA for root induction. All cultures were incubated at $25^{\circ} \mathrm{C}$ in a 16 -hour photoperiod. The embryo-rescued plants with well-developed root system were hardened for 4-8 days at $10-12^{\circ} \mathrm{C}, 14$-hour photoperiod and then transferred into pots with soil for normal growth under glasshouse conditions [20].

\section{Characterization of hybrids}

Hybrid identity of F1 plants was confirmed by morphological examination, chromosome analysis and further characterize by simple sequence repeat (SSR) analysis.

Chromosome counts were carried out on root tips from hybrid plants and pretreated with $0.002 \mathrm{M}$ 8-hydroxyquinoline for 4 hours. Material was fixed in 3:1 alcohol-glacial acetic acid, hydrolyzed in $1 \mathrm{~N} \mathrm{HCl} 60^{\circ} \mathrm{C}$ for $6 \mathrm{~min}$ and stained with leuco-basic fuchsine $30 \mathrm{~min}$, and then squash preparations were made using $45 \%$ acetic acid [21]. About $0.3 \mathrm{~g}$ fresh leaves were used to extract genomic DNA using the cetyl-trimethyl-ammonium bromide (CTAB) method [22]. An Eppendorf protein and nucleic determine instrument was used for determining DNA concentration. Primer sequences for SSR markers obtained from various sources [23-25] were used (Tab. 1). The SSR reactions were performed in a $20 \mu \mathrm{l}$ volume containing $60 \mathrm{ng} \mathrm{DNA}, 0.5 \mu \mathrm{mol} / \mathrm{l}$ forward and reverse primer, $0.2 \mathrm{mmol} / \mathrm{l} \mathrm{dNTPs,} 1.0 \mathrm{mmol} / 1 \mathrm{MgCl}_{2}$, and $0.5 \mathrm{U}$ Taq DNA polymerase. The PCR procedure was programmed at $95^{\circ} \mathrm{C}$ for $2 \mathrm{~min}, 94^{\circ} \mathrm{C}$ for $30 \mathrm{~s}, 55^{\circ} \mathrm{C}$ for $30 \mathrm{~s}$, $72^{\circ} \mathrm{C}$ for $30 \mathrm{~s}$ for $35 \mathrm{cycles}$, and then $72^{\circ} \mathrm{C}$ for $10 \mathrm{~min}$. The products were separated on $5 \%$ vertical polyacrylamide gel. The gel was run at a $150 \mathrm{~V}$ constant voltage for 1 to $1.5 \mathrm{~h}$ before silver staining.

For cytological studies young anthers were fixed in Carnoy solution and squashed in $1 \%$ acetocarmine [26].

\section{Results}

\section{Embryo culture}

After 1-2 weeks of culture, the ovaries were observed turgid. Of all the 100 ovaries only 11 embryos developed to the mature cotyledonary stage after 3 weeks in culture (Tab. 2). Of 11 cultured embryos, 4 embryos germinated (germination rate $=36.3 \%$ ) with the help of embryo culture in vitro. The 4 embryos germinated halted their development when their shoots were $1 \mathrm{~cm}$ in length, and did not lead to whole plants. Regeneration plantlets were induced from the cotyledon sections of the 4 germinated embryos on MS

Tab. 1 Primers for SSR marker assays.

\begin{tabular}{lll}
\hline Primer name & Forward primers & Reverse primers \\
\hline FITO 137 & ATGGGTAAGTCTCGTAAATG & AAACCGAATAAACCGAAA \\
Na10F06 & CTCTTCGGTTCGATCCTCG & TTTTTAACAGGAACGGTGGC \\
Na12H09 & AGGCGTCTATCTCGAAATGC & CGTTTTTCAGAATCTCGTTGC \\
Ni4A03 & ACACAGAAACATCAAACATACC & GGACCGGTTTTATTTGTTCG \\
Ol09A06 & TGTGTGAAAGCTTGAAACAG & TAGGATTTTTTTGTTCACCG \\
Ol10F11 & TTTGGAACGTCCGTAGAAGG & CAGCTGACTTCGAAAGGTCC \\
Ol12F11 & AAGGACTCATCGTGCAATCC & GTGTCAGTGGCTACAGAGAC \\
Na14D09 & GATCAACGTAAGGTCGCCTC & GAATCCAACGGATCAGAAGC \\
\hline
\end{tabular}


Tab. 2 Embryo production from ovary culture in hybridizations between B. campestris ssp. chinensis Makino and R. sativus.

\begin{tabular}{lcccc} 
Crosses & No. of cultured ovaries & No. of embryos produced & No. of embryos survived & Rate of germination (\%) \\
\hline $\begin{array}{l}\text { B. campestris ssp. chinensis } \\
\text { Makino } \times \text { R. sativus }\end{array}$ & 100 & 11 & 4 & 36.3 \\
\hline
\end{tabular}
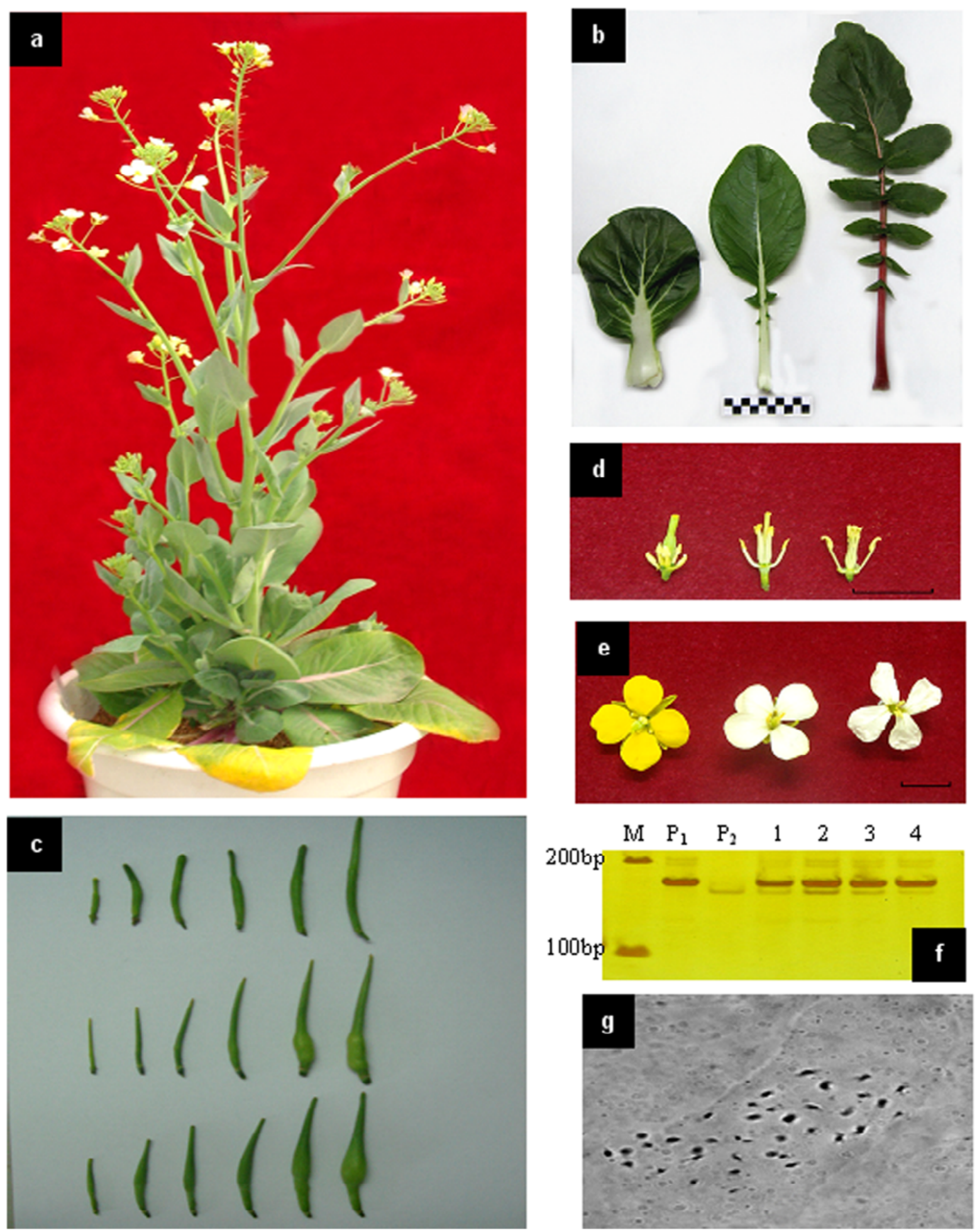

Fig. 1 Hybrid identity of F1 plants. a Flowering stage of F1. b Leaves of B. campestris (left), R. sativus (right) and F1 (middle). c Siliques of B. campestris (up), R. sativus (middle) and F1 (bottom). d Stamens and pistil of B. campestris (left), R. sativus (right) and F1 (middle). e Flower of B. campestris (left), R. sativus (right) and F1 (middle). f Amplification results of primer Na14D09 on B. campestris (P1), R. sativus (P2) and F1 (1, 2, 3 and 4). g Chromosome number of F1 $(2 \mathrm{n}=4 \mathrm{x}=38 ; 1000 \times)$. Scale bars: $\mathbf{b}-\mathbf{e} 1 \mathrm{~cm}$. 
medium supplemented with $2.0 \mathrm{mg} / \mathrm{l}$ 6-benzyladenine and $0.1 \mathrm{mg} / \mathrm{l} \mathrm{NAA}$, and then they were transplanted to the root induction medium. A total of 4 lines were obtained with several numbers of plants.

\section{Characterization of hybrids}

All hybrid plants were morphologically uniform and grew vigorously.

The hybrids were intermediate in size and shape (Fig. 1a). They resembled the non-heading Chinese cabbage in the long-lived habit, the plant status, the vernalization requirement, the petiole color (Fig. 1b). Petiole and silique shape, leaf venation pattern and flower color were more similar to those of radish (Fig. 1c-e). Upon examination of the flowers, these were found to have normal pistil, but rudimentary anthers with non-functional pollen grains (Fig. 1d).

The somatic chromosome number of the regenerated plants was counted at the middle stage of cell division. The results showed that the chromosome number of all plants tested was 38 (Fig. 1g), indicating that these regenerated plants were all true hybrids of $B$. campestris $(2 \mathrm{n}=4 \mathrm{x}=40)$ $\times R$. $\operatorname{sativus~}(2 \mathrm{n}=4 \mathrm{x}=36)$.

Out of 8 SSR primer pairs, only 1 pair (12.5\%) SSR primers (Tab. 1) had polymorphic between parents gnomic DNA. All of the hybrids were tested by SSR analysis with 8 primer pairs. SSR analysis indicated that the hybrids had hybrid patterns containing characteristic bands from $R$. sativus in addition to the B. campestris, which exhibits codominant (Fig. 1f).

\section{Discussion}

The present paper describes the production of a new allotetraploid by intergeneric hybridization between

\section{Acknowledgments}

Authors are grateful to Jiangsu province science and technology support program (BE201130172) for financial support.

\section{Authors' contributions}

The following declarations about authors' contributions to the research have been made: designing research: ZSN; performing experiments: ZSN, SCZ, ZJS; writing the manuscript: ZSN, SCZ, LY.

\section{References}

1. Grant V. Plant speciation. New York, NY: Columbia University Press; 1981.

2. Haufler CH, Soltis DE. Genetic evidence suggests that homosporous ferns with high chromosome numbers are diploid. Proc Natl Acad Sci USA. 1986;83(12):4389-4393. http://dx.doi.org/10.1073/ pnas.83.12.4389

3. Shaked H, Kashkush K, Ozkan H, Feldman M, Levy AA. Sequence elimination and cytosine methylation are rapid and reproducible responses of the genome to wide hybridization and allopolyploidy in wheat. Plant Cell. 2001;13(8):1749-1759. http://dx.doi.org/10.1105/ TPC. 010083

4. Adams KL, Wendel JF. Novel patterns of gene expression in polyploid plants. Trends Genet. 2005;21(10):539-543. http://dx.doi.org/10.1016/j. tig.2005.07.009

5. Chen ZJ, Ni Z. Mechanisms of genomic rearrangements and gene expression changes in plant polyploids. BioEssays. 2006;28(3):240-252. http://dx.doi.org/10.1002/bies.20374 autotetraploid non-heading Chinese cabbage (Brassica campestris ssp. chinensis Makino) and autotetraploid radish (Raphanus sativus L.) through ovary culture and embryo rescue. We found that the production of allotetraploid was about $4 \%$, which compared favorably with percentages reported for B. napus $\times$ D. siifolia (11.5\%) [27] and B. campestris $\times$ $M$. arvensis (5\%) [19]. The interspecific hybridizations we obtained confirm that crossing between tetraploid parents is a useful method in producing synthetic allotetraploid. In addition, the use of two tetraploid parents offers a good model for the study of a one-step process of polyploidization whereby, in nature, unreduced gametes of two diploid parents can yield allotetraploid progeny.

For cytological studies, no functional pollen grains have been found and no seeds were obtained by selfing and crossed with two parents, which shows that the F1 maybe male sterile.

The intergeneric hybrids between non-heading Chinese cabbage and radish were successfully produced and characterized. These will be the base material for developing the whole set of R. sativus-B. campestris additions in future for genome analysis and chromosomal localization of genes. In addition, the agronomical potential of the hybrid progenies obtained by selfing or backcross are under current evaluation on their advancement, improvement and exploitation. Furthermore, this hybrid plant offers an ideal model system to study the response to genomic changes from defined parents, such as structural rearrangements on the chromosome level [28] and sequence level [29,30], regulation of gene expression [31], activation of transposons [32], and amplification, reassortment, or elimination of highly repetitive sequences [33] and low-copy sequences [34].

6. Beaulieu J, Jean M, Belzile F. The allotetraploid Arabidopsis thalianaArabidopsis lyrata subsp. petraea as an alternative model system for the study of polyploidy in plants. Mol Genet Genomics. 2009;281(4):421435. http://dx.doi.org/10.1007/s00438-008-0421-7

7. Ramsey J, Schemske DW. Pathways, mechanisms, and rates of polyploid formation in flowering plants. Ann Rev Ecol Syst. 1998;29(1):467-501. http://dx.doi.org/10.1146/annurev.ecolsys.29.1.467

8. Thao NTP, Ureshino K, Miyajima I, Ozaki Y, Okubo H. Induction of tetraploids in ornamental Alocasia through colchicine and oryzalin treatments. Plant Cell Tissue Organ Cult. 2003;72(1):19-25. http:// dx.doi.org/10.1023/A:1021292928295

9. Möllers C, Iqbal MCM, Röbbelen G. Efficient production of doubled haploid Brassica napus plants by colchicine treatment of microspores. Euphytica. 1994;75(1-2):95-104. http://dx.doi.org/10.1007/ BF00024536

10. Chen ZJ, Wang J, Tian L, Lee HS, Wang JJ, Chen M, et al. The development of an Arabidopsis model system for genome-wide analysis of polyploidy effects. Biol J Linn Soc. 2004;82(4):689-700. http://dx.doi. org/10.1111/j.1095-8312.2004.00351.x

11. Lelivelt CLC, Lange W, Dolstra O. Intergeneric crosses for the transfer of resistance to the beet cyst nematode from Raphanus sativus to Brassica napus. Euphytica. 1993;68(1-2):111-120. http://dx.doi. org/10.1007/BF00024160

12. Kolte SJ, Bordoloi DK, Awasthi RP. The search for resistance to major diseases of rapeseed and mustard in India. In: Proceedings of the 8th international rapeseed congress. Saskatoon: Organizing Committee of the Eighth International Rapeseed Congress; 1991. p. 219-225. 
13. Thierfelder A, Hackenberg E, Nichterlein K, Friedt W. Development of nematode-resistant rapeseed genotypes via interspecific hybridization. In: Proceedings of the 8th international rapeseed congress. Saskatoon: Organizing Committee of the Eighth International Rapeseed Congress; 1991. p. 269-273.

14. Peterka H, Budahn H, Schrader O, Ahne R, Schütze W. Transfer of resistance against the beet cyst nematode from radish (Raphanus sativus) to rape (Brassica napus) by monosomic chromosome addition. Theor Appl Genet. 2004;109(1):30-41. http://dx.doi.org/10.1007/ s00122-004-1611-2

15. Long MH, Xing GM, Okubo H, Fujieda K. Cross compatibility between Brassicoraphanus (Brassica oleracea $\times$ Raphanus sativus) and cruciferous crops, and rescuing the hybrid embryos through ovary and embryo culture. J Fac Agric Kyushu Univ. 1992;37(1):29-39.

16. Agnihotri A, Shivanni KR, Lakshmikumaran MS. Micropropagation and DNA analysis of wide hybrids of cultivated Brassica. In: Proceedings of the 8th international rapeseed congress. Saskatoon: Organizing Committee of the Eighth International Rapeseed Congress; 1991. p. 151.

17. Warwick SI, Black LD. Molecular systematics of Brassica and allied genera (subtribe Brassicinae, Brassiceae) - chloroplast genome and cytodeme congruence. Theor Appl Genet. 1991;82(1):81-92. http:// dx.doi.org/10.1007/BF00231281

18. Murashige T, Skoog F. A revised medium for rapid growth and bio assays with tobacco tissue cultures. Physiol Plant. 1962;15(3):473-497. http://dx.doi.org/10.1111/j.1399-3054.1962.tb08052.x

19. Takahata Y. Production of intergeneric hybrids between a C3-C4 intermediate species Moricandia arvensis and a C3 species Brassica oleracea through ovary culture. Euphytica. 1990;46(3):259-264. http:// dx.doi.org/10.1007/BF00027226

20. Zhang GQ, Tang GX, Song WJ, Zhou WJ. Resynthesizing Brassica napus from interspecific hybridization between Brassica rapa and B. oleracea through ovary culture. Euphytica. 2004;140(3):181-187. http://dx.doi.org/10.1007/s10681-004-3034-1

21. Tashiro Y. Cytogenetic studies on the origin of Allium wakegi Araki. Agr Saga Univ. 1984;56:1-63.

22. Saghai-Maroof MA, Soliman KM, Jorgensen RA, Allard RW. Ribosomal DNA spacer-length polymorphisms in barley: mendelian inheritance, chromosomal location, and population dynamics. Proc Natl Acad Sci USA. 1984;81(24):8014-8018. http://dx.doi.org/10.1073/ pnas.81.24.8014

23. Kim JS, Chung TY, King GJ, Jin M, Yang TJ, Jin YM, et al. A sequencetagged linkage map of Brassica rapa. Genetics. 2006;174(1):29-39. http://dx.doi.org/10.1534/genetics.106.060152
24. Choi SR, Teakle GR, Plaha P, Kim JH, Allender CJ, Beynon E, et al. The reference genetic linkage map for the multinational Brassica rapa genome sequencing project. Theor Appl Genet. 2007;115(6):777-792. http://dx.doi.org/10.1007/s00122-007-0608-Z

25. Cui XM, Dong YX, Hou XL, Cheng Y, Zhang JY, Jin MF. Development and characterization of microsatellite markers in Brassica rapa ssp. chinensis and transferability among related species. Agr Sci Chin. 2008;7(1):19-31. http://dx.doi.org/10.1016/S1671-2927(08)60018-8

26. Nanda Kumar PB, Shivanna KR. Intergeneric hybridization between Diplotaxis siettiana and crop brassicas for the production of alloplasmic lines. Theor Appl Genet. 1993;85(6-7):770-776. http://dx.doi. org/10.1007/BF00225018

27. Batra V, Prakash S, Shivanna KR. Intergeneric hybridization between Diplotaxis siifolia, a wild species and crop brassicas. Theor Appl Genet. 1990;80(4):537-541. http://dx.doi.org/10.1007/BF00226756

28. Leitch IJ, Bennett MD. Polyploidy in angiosperms. Trends Plant Sci. 1997;2(12):470-476. http://dx.doi.org/10.1016/S1360-1385(97)01154-0

29. Song K, Lu P, Tang K, Osborn TC. Rapid genome change in synthetic polyploids of Brassica and its implications for polyploid evolution. Proc Natl Acad Sci USA. 1995;92(17):7719-7723. http://dx.doi. org/10.1073/pnas.92.17.7719

30. Wendel JF, Schnabel A, Seelanan T. Bidirectional interlocus concerted evolution following allopolyploid speciation in cotton (Gossypium). Proc Natl Acad Sci USA. 1995;92(1):280-284. http://dx.doi. org/10.1073/pnas.92.1.280

31. Comai L, Tyagi AP, Winter K, Holmes-Davis R, Reynolds SH, Stevens $\mathrm{Y}$, et al. Phenotypic instability and rapid gene silencing in newly formed Arabidopsis allotetraploids. Plant Cell. 2000;12(9):1551-1567. http:// dx.doi.org/10.1105/tpc.12.9.1551

32. Hanson RE, Islam-Faridi MN, Crane CF, Zwick MS, Czeschin DG, Wendel JF, et al. Tyl-copia-retrotransposon behavior in a polyploid cotton. Chromosome Res. 2000;8(1):73-76. http://dx.doi. org/10.1023/A:1009239522541

33. Salina EA, Ozkan H, Feldman M. Subtelomeric repeat reorganization in synthesized amphiploids of wheat. In: Proceedings of the international conference on biodiversity and dynamics of systems, North Eurasia. Novosibirsk: ICG; 2000. p. 102-105.

34. Liu B, Vega JM, Segal G, Abbo S, Rodova M, Feldman M. Rapid genomic changes in newly synthesized amphiploids of Triticum and Aegilops. I. Changes in low-copy noncoding DNA sequences. Genome. 1998;41(2):272-277. http://dx.doi.org/10.1139/g98-011 